\title{
FRICTIONS BETWEEN HETEROGENEOUS WORLDS
}

\author{
Bernard Ferriès, Michel Léglise \\ Laboratoire Li2a, École Nationale Supérieure d'architecture de Toulouse \\ 83, Rue Aristide Maillol BP 1329, 31106 TOULOUSE Cedex 1, France \\ Bernard Ferriès (ferries@laurenti.com), \\ Michel Léglise, (mleglise@free.fr)
}

Remisión Artículo: 2-5-2007

Keywords: Planning, architecture, GIS, City models

\begin{abstract}
Geography, architecture and town planning found a new cooperation area thanks to recent interoperability progresses. Geographers drawing up maps of large areas, town planners dealing with cities or districts and architects trying to integrate buildings to these districts are the links of a chain which embraces various professions applying different codified and standardised modes of representation. These modes result from long practices which have succeeded in capturing interpretations of their domains and of the objects while complying with the need for practicality and efficiency.

The aim of this paper is to give an overall view of the critical friction points between these worlds, allowing a rational and reasonable reception of the merged object. The corresponding computer tools are already available or about to be.

We also make some recommendations concerning the implementation of an information system able to take into account the needs of all the professions involved in the process. It is mandatory to preserve the culture of each profession and respect everybody point of view to achieve a good level of integration and a better communication. Examples will be chosen at the frontiers between architecture and town planning.
\end{abstract}

J.L. Borges showed us the limits beyond which the world as a whole can no longer be accounted for: the map could be as large as the territory to perfectly match it. But it would then turn into a territory on the road to oblivion.

\section{Introduction}

Many local authorities have acquired geographical information systems (GIS) in order to manage the data related to their own territory and more particularly to the towns. In most GIS, the buildings are represented by their footprint, i.e with a $2 \mathrm{D}$ contour. Attempts have already been made in order to represent the shell of the buildings and they tend to be even more numerous today. Urban modelling is at the junction of two worlds: that of the architect who models a project in order to insert the building on a site and to construct it and that of the person in charge of modelling all the elements of an urban site, among which buildings.

This friction zone is a fascinating topic. Today's technological breakthroughs enable us to explore new avenues and to change scales - from building to territory and conversely.

When the two worlds remain distinct from each other, the actors work in their own sector with an impact restricted to their field of application.

When both worlds meet, new fascinating opportunities arise but they can also lead to frictions resulting from the newly introduced arrangements and interactions. 
Moreover, several information providers offer more and more « photorealistic ${ }^{1}$ documents as if the world could be seen at all scales, from 1 to the infinitely small.

This paper intends to better apprehend the different worlds, to characterize some of their frictions and to make some recommendations so that these now digitally connected fields work on a joint basis. The different professions must keep their identity and their operating modes but must also allow for a consistent interoperability facilitating the deployment of new and better concerted activities.

\section{3D City models: a review of some French initiatives}

\subsection{The City of Rennes}

This service became available to the general public at the beginning of 2005; it is a real novelty in term of large territory accessibility in 3-D on the Internet.

The project has been supported by the region of Brittany in the framework of a call for projects launched in 2003 aiming at developing high flow networks.

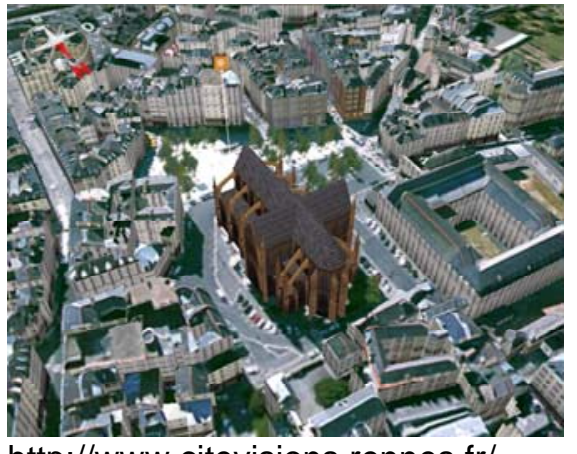

http://www.citevisions.rennes.fr/

38000 buildings are described. The model has been automatically generated, based on the footprint of the buildings extracted from urban data, the height of buildings and aerial views. Some outstanding buildings such as the cathedral opposite have been modelled in great details.

This is a "plausible representation of the city extrapolated from real data" ${ }^{2}$. We note the shift in meaning from "realistic" to "plausible", which raises the issue of the type and quality of data represented in some of these systems.

The aim of the project is to "offer information and proximity services to the inhabitants of Rennes thanks to the use of multimedia technologies quite similar to video games".

\footnotetext{
${ }^{1}$ This general trend considers aerial or satellite images as the universal equivalent of what can be seen, which raises other questions outside the scope of this article.

${ }^{2}$ http://www.citevisions.rennes.fr/scripts/fr/01_projet/01d_systeme.htm
} 


\subsection{The City of Cannes}
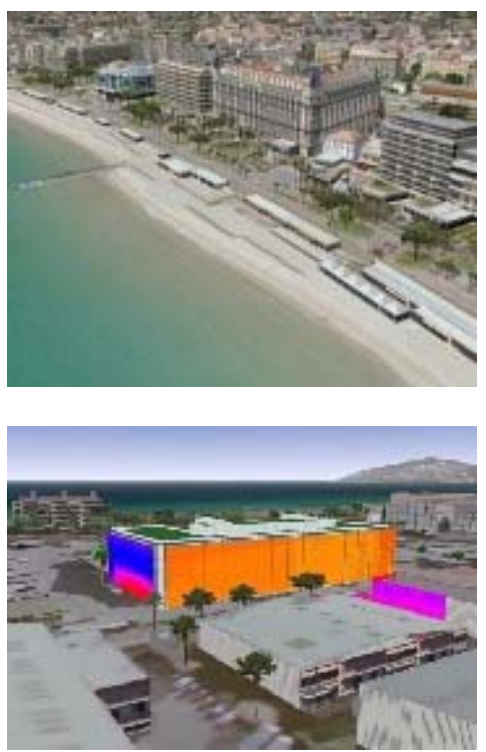

http://salle-immersive.cstb.fr
This more recent project has been awarded the "Laval Virtual 2006 " prize. It consisted in designing a detailed virtual mockup of the Cannes conurbation, i.e 22000 buildings. The following objects have been modelled from aerial views: the trees higher than five metres, urban furniture, details of roofs and textures. Some buildings - like in Rennes - have been modelled in greater details.

Virtual tours via the Internet, services to the city dwellers to help them pinpoint and assess the distance from their home to public places (schools, day nurseries...), count among the possible applications.

This digital mock-up is a virtual platform which will integrate future building projects with a will to impose in the short term the delivery of 3-D architect and engineering data in order to conduct simulations of all types (acoustic, thermal, light effects).

Opposite: the colour of the facades of a future building which clearly shows its exposure to plane noises.

\subsection{Toulon, Provence méditerranée association of communes and IGN ${ }^{3}$}

This joint project aims at producing 3D representations of buildings from various sources (aerial views, terrain digital model.) The end product will be available on CityGML format.

"A total of $20 \mathrm{~km}^{2}$, the covered areas are those corresponding to projects such as urban renovation, building of tramway or other significant works. The final "Bati 3D" project will offer to the three stakeholders: high resolution ortho-photographies of all the communes of the Toulon conurbation (20 cm resolution for the TPM communities (islands excluded) and the shoreline of the SCoT; $40 \mathrm{~cm}$ resolution otherwise).."

One can see that data can be represented differently, by defining their accuracy according to their geolocalization and clearly delineated goals ; if "Bati 3D" is a valuable aid to decisionmaking tool for the above-mentioned communities, the presentation of projects will be clearer and more cogent for the citizens, especially in the framework of " public surveys"

\footnotetext{
${ }^{3}$ Institut Géographique National (www.ign.fr/)

${ }^{4}$ http://www.geomag.fr/new/article-page-newsletter-A ID-64.html

${ }^{5}$ http://www.ibatiment.com/document_3091.html
} 


\subsection{The Yellow pages}

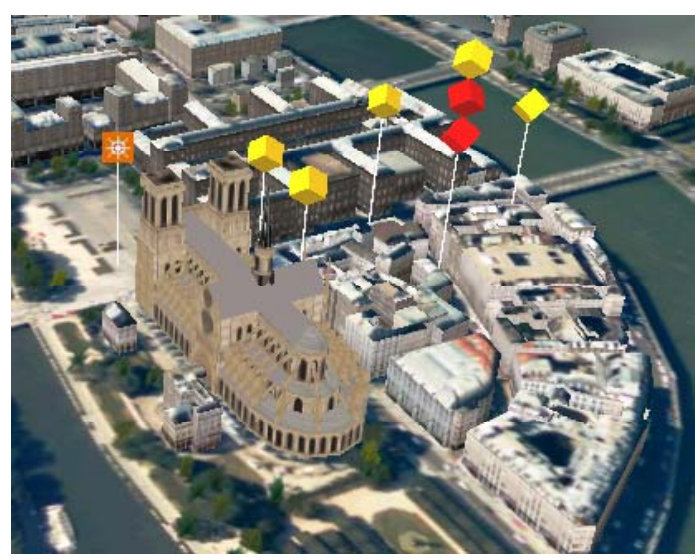

Above, the restaurants near Notre Dame de Paris.
Since September $11^{\text {th }} 2006$, Pagesjaunes.fr have offered a beta version ${ }^{6}$ of a new service thanks to which the Net surfer can browse through the 3D mock-up of the cities of Rennes and Paris.

The end-user can localize with accuracy the sites and their corresponding activities. Data are not really accurate. The aim is to have true-to-life images, facades are generated from a catalogue including 500 models.

In this case, realism is doing without accurate data and the facades obtained result from calculations more than data as such. Descriptions and analyses of this project and of its technical infrastructure are discussed in [d'Erceville 2006]. A three-month experience is ongoing: "The aim is to test the Internet users' enthusiasm for this new tool"

\subsection{Google Earth}

Large American cities are modelled in 3D at LOD1 level, according to the level of detail scale defined in CityGML ${ }^{7}$. The system also includes indications on activities (restaurants, hotels, airports....) and their location. It is the foundation of Google's economic model which facilitates a pay access to targeted information.

Even though it is not French, this system is a widely used concept in this country and one will focus on the following initiative: Google now circulates for free "Google sketch up », a userfriendly 3D powerful modeller. Thanks to « 3D Ware House » system, each and everybody is free to issue a 3D model ${ }^{8}$, briefly describing its nature (real, projected, historical object or fantasy).

The system is highly permissive: it is quite possible to download a model, modify and publish it in a competing version. When modelling existing buildings, which is the fairest and were there only one, how to rate it?

\footnotetext{
${ }^{6}$ http://v3d.pagesjaunes.frl

7 "CityGML is a common information model for the representation of 3D urban object. [...] CityGML does not only represents the graphical appearance of city models but especially takes care of the representation of the semantic resp. thematic properties, taxonomies and aggregations of Digital Terrain Models, sites (including buildings, bridges, tunnels), vegetation, water bodies, transportation facilities, and city furniture. The underlying model differentiates five consecutive levels of detail (LOD)". [City GML 2006].

${ }^{8}$ Google 3D Ware House : Search, share and store 3D models http://sketchup.google.com/3dwarehouse/
} 


\subsection{Comments}

Google Earth, Géoportail ${ }^{9}$ and the Yellow pages have all something in common: they encourage a huge number of log-ins by Internet surfers and a spontaneous and distributed control of the quality of the modelling depending on the knowledge the user has of the real state of a building and of its surrounding. Blogs clearly highlight some errors inherent to automatic processing: a church transformed into a ten-storey building... Verisimilitude tends, as already stated in Rennes, to take precedence over realism.

Urban modelling should be automated as much as possible for obvious economic reasons so as to make it available to the largest possible number of users. Automation, like character recognition, cannot be $100 \%$ reliable. We can of course rely on the city dwellers to indicate errors, which means delegating the quality control of an Information system to the occupants of the territory concerned.... We can draw a parallel with the open source: software programs are considered as highly reliable because they are used by a great number of people who come across problems which are then corrected quite rapidly by the highly reactive developers.

Technique seems to anticipate still unexpressed needs. For instance, the needs of the 3D version of "yellow pages" are not listed and the success of the test performed will be appraised by the number of Internet surfers who will have tested the service. To do what? Who will ever know?

\section{Worlds and professions}

Each profession likely to use these 3D models has its own characteristics derived from a specific scientific and technical culture and represents a world with expressed needs. Each world (geography, town planning, architecture or building) has its own modes of description and representation of useful data. These different worlds also share some features. We will try to list some of their major characteristics.

The different professions have built their own different world. Each profession has its own viewpoint, codes, customs and tools. Representations and its uses are at the core of professional practices:

- to be operational

- $\quad$ to be shared without ambiguity

- to avoid any interpretation at the time of implementation.

Most professions have conducted a codification of scales. To obtain unambiguous codes, most of them use a small number of scales to which the tools will adapt (e.g the "cutch" in architecture).

Today, each world has its own categories of software and software give a clear view of the goals targeted by each world since the software functionalities clearly delineate the needs in term of data and expected results:

- GIS aims at representing a territory for aid to decision-making (town planning master plan, flood risk areas, socio-economic network), information to the citizen, etc.

- CAD (Computer aided design) software describes a building project in order "to do", to build, hence a high level of details which has nothing to do with the corresponding descriptions in the GIS.

- CAFM (Computer Aided Facility Management) tools represent existing buildings for asset management, property management, and/or facility management.

\footnotetext{
${ }^{9}$ http://www.geoportail.fr
} 


\subsection{Scale and zoom: the object, its definition and size of representation}

Each object has real dimensions in the real world. The scale is the ratio between the real size of the object and the size of its representation. Scaling and zooming are distinct semantic operations. The former may intend to define the shape of the map of the territory, the latter can help me to make up for my short-sightedness for example.

Other parameters specific to each craft are also linked to the scales. That is how a set of conventions

accepted by all (designers and readers of a plan) makes it possible to read a document without any ambiguity although without having to represent all objects at all scales. An example are the "visualization scales" in the Krépis project [Krépis, 1988].

In this project the details of a door frame whose scale is under $1 / 20$ are not represented. The example quoted hereafter shows that a door with a different scale can be represented differently and that using a zoom helps maintain the same size for an object represented at different scales on paper.

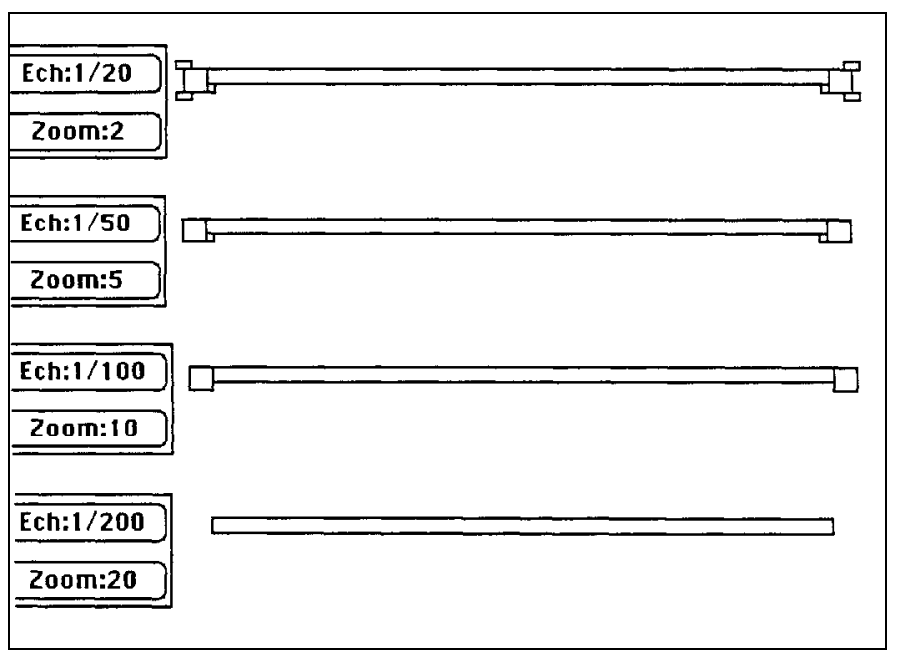

One can introduce the concept of minimal and maximal "visualization scale".

This range is linked with the shape representation of the object and not with the layers as mentioned below.

Source: [Goulette, Léglise \& al., 1988].

Note: zoom is a-dimensional $(1 / 5$, $1, \ldots)$

\subsection{Layers and objects : anchoring objects onto layers, visibility of layers}

Besides, the concept of layer is widely used both in architecture and town-planning. Each object is attached to a layer and each layer supports a set of objects. The overall object is seen by selecting relevant layers.

The scale also helps to adjust through a series of intervals the final viewing of some layers and consequently of some types of objects provided that each type has been placed on an adequate layer. 


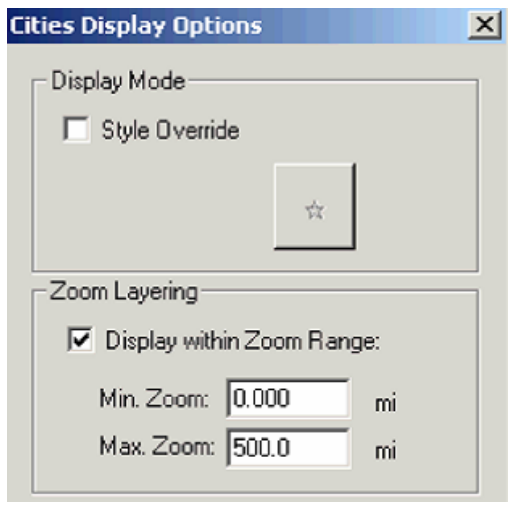

Example from GIS software [MapInfo, 2006] :

Zooms conditioning the display of the layer :

- Min : zoom from which the layer is displayed

- Max : zoom beyond which the layer is no longer displayed

Note: the zoom is expressed in maximum distance (miles) which can be displayed on a screen.

Another example of ambiguous wording.

One can see that each profession has its own subtle means to do away with representations which would interfere with a view at a given scale and even if the view was zoomed, the objects unseen at this given scale would not yet become visible. On the other hand, one knows that the representations that the new generation of image databases, as supplied by firms like Google earth, offer the potential view of a blade of grass even with a $10 \mathrm{kms}$ distance and with whatever the zoom, thereby becoming increasingly tangible as one gets closer.

\subsection{Common traits}

What is essential for a profession is to have a set of cogent, updated, reliable data adapted to a task. Some professions can be data consumers or data producers according to case. And no profession whatsoever can tolerate pointless definition levels. The profession tools handle "singular" and not "universal" data linked to the related tasks. Consumption and production need tools relevant to the profession; these tools may become totally irrelevant to another profession and even antinomic.

\section{Boundaries}

The interest of cooperation at the boundary has already been demonstrated in many papers on the subject. Several aspects have been reviewed like interoperability, collaborative work, data representation, modelling capacities ${ }^{10}$, etc.

We will rather focus on the reasons why there has been a recent and increasing interest for "deleting the boundary" and introducing interoperability between GIS and CAD/CAFM tools. We have already made suggestions in order to improve this interoperability [Ferriès, 2001], [Ferriès, 2004], [Kolbe \& al., 2004].

We will also propose reasons related to the software currently used, to standards maturity and to the interoperability progress which facilitates the introduction of new fields of application.

\subsection{Actors' level of equipment}

Most architects are equipped with CAD tools. French local and regional authorities entrust GIS with the management of data on their territory ${ }^{11}$ and more and more owners and facility managers opt for setting up dedicated information systems.

\footnotetext{
${ }^{10}$ For example CSG and BREP representations are used in CAD/FM tools whereas Only Brep is being used with GML and KML.

${ }^{11}$ GIS map in http://www.ieti.fr/ogl/Obs_IETI.asp
} 
When each actor has its own tools and when the technical feasibility has been evidenced, new requirements in term of exchange and cooperation can arise.

As an example, the General Council of Gironde has had an interface developed between its $\mathrm{SIG}^{12}$ and its CAFM software ${ }^{13}$ :

- a school can be selected in the patrimony management software, and then located on a map managed by the GIS.

- a school can be selected in the GIS by pinpointing its coverage; it thus gives access to the information on the school contained in the CAFM software.

\subsection{Standards}

In the building sector, IFC ${ }^{14}$ become a mature alternative to exchanges of DWG files whose limitations are very well known. IFC are implemented by most CAD and CAFM editors, and a lot of third party editors. On the GIS side, a set of standards co-developed by OGC ${ }^{15}$ and ISO $\mathrm{TC} 211^{16}$ is now available. So, there is a genuine interoperability in each world and also between GIS and CAD/FM thanks to the results achieved by the IFG $^{17}$ project.

Conversion tests between GML and IfcXML have been conducted and several prototypes have thus been developed. Cooperation between OGC and IAI will permit the integration of CAD/GIS functions to the web services packages being developed.

\subsection{Fields of application at the CAD/GIS junction}

\subsubsection{Risk management}

A presentation of exchanges between CAD and GIS was made in 2003 at an event organized by IAI [Miller \& Moulton, 2003]. Since then, the demand has become more precise: aid to decision-making for intervention, staff training to hazardous situations...

Interoperability between CAD/GIS permits the development of new applications combining the description of the environment of a building and the description of the site of the intervention.

\footnotetext{
${ }^{12}$ Geoconcept: http://www.geoconcept.com/fr/

${ }^{13}$ Abyla : http://www.abyla.fr/

${ }^{14}$ Industrial Foundation Classes. http://www.iai-international.org/

${ }^{15}$ Open Geospatial Consortium, http://www.opengeospatial.org/

${ }^{16}$ ISO/TC 211 Geographic information/Geomatics : http://www.isotc211.org/

${ }^{17}$ IFG stands for IFC for GIS. This set of new classes will be part of the next IFC release (IFC 2x3G)
} 


\subsubsection{Town planning}

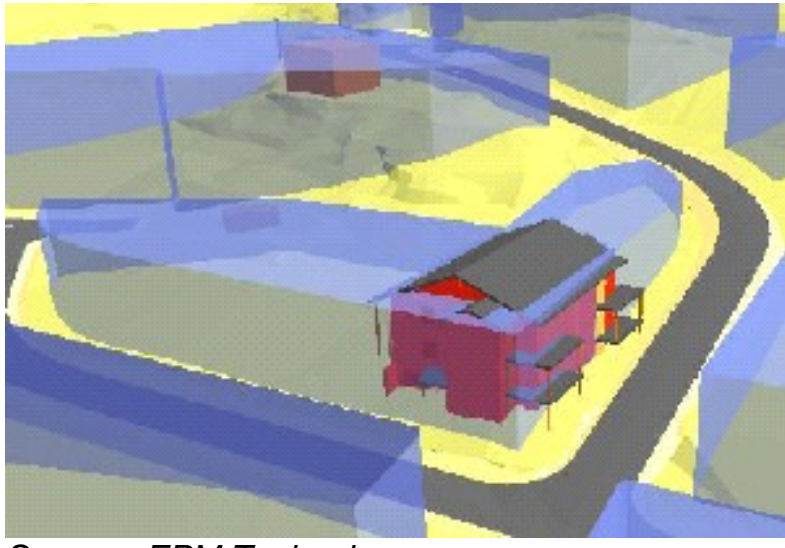

Source : EPM Technology
The Norwegians have chosen to "dema-terialize" the building permits process $^{18}$.

Several stages in the process have been planned. For the most advanced, the building project will be available in IFC format and confronted to planning constraints thanks to data extracted from a GIS.

An application consisting in an automated control of rules is being developed. As an example, it checks whether a building is within the limits of allowed volume.

\subsubsection{Information systems updating}

CAD/GIS interoperability is quite useful since it can facilitate the updating procedures for a territorial information system from CAD/FM data on the existing or projected buildings.

In the framework of the CODES ${ }^{19}$ project, Ordnance Survey attempts to encourage stakeholders in the building sector to produce geographical information by paying for the delivery of drawing files dealing with building projects.

\section{Exchanges and frictions at the boundaries}

Professions really need cooperation at the boundaries. We have not reached the stage of fully inter-operable 3D models and the representation modes differ largely (from a cultural and practical viewpoint). Yet, some practical exchanges take place although not without predictable frictions.

These normal, natural frictions between heterogeneous worlds can be subdivided into :

- defence of private domains (of privileges in a given area, of ways of doing, of property of univocal representation in this area)

- reciprocal suspicion: are the data I have obtained good data ? have they been generated with as much care as expected, have they been checked, if yes by whom, to what extent are they accurate ?

- can someone's data injected into someone else's data be efficiently used by others (see above)?

- what about the global reliability of data when synthetic data are re-injected into in situ collected data in order to obtain a "whole" ?

o Do the less reliable data weaken the whole or is it possible to isolate the "good "from the" bad"? (to separate the wheat from the chaff)

\footnotetext{
${ }^{18}$ http://www.byggsok.no/english/english.php

${ }^{19}$ Collection Of Data from External Ressources

http://www.ordnancesurvey.co.uk/oswebsite/business/codes/
} 
- Are data structures inter-operable or are there insuperable barriers between the different representation modes or : how to proceed to maintain a coherent global representation derived from heterogeneous worlds (structural, computer, semantic coherence)

\section{Cooperation and hybridation at the boundaries}

All these issues invite us to sketch an "ideal" urban information system by making some suggestions. Structuring efforts seem to be necessary in order to avoid being swept away by the model of single representation like GoogleEarth. Our recommendations can be summarized in nine points.

\subsection{Massive introduction of metadata}

Metadata are data which describe a resource and gather all the data to be collected and made available in order to describe the resource.

Setting up a GIS means acquiring information coming from different sources (parcels, network managers...) which implies the development of a geographic information market. As it is essential to know the products available on the market and their quality, a metadata model has been defined (ISO 19115). This model is used to draw up catalogues of geographical data and supplies information on:

- data producer (description of the geographical range of the resource, information on the possible uses, legal constraints).

- geographical coverage

- latest update

- contents, its presentation and maintenance

- reliability

- geometrical, temporal, semantic accuracy, etc...

Definition, context and fields of application in the framework of this norm have been clarified [CNIG, 2006]. Three levels of metadata are identified :

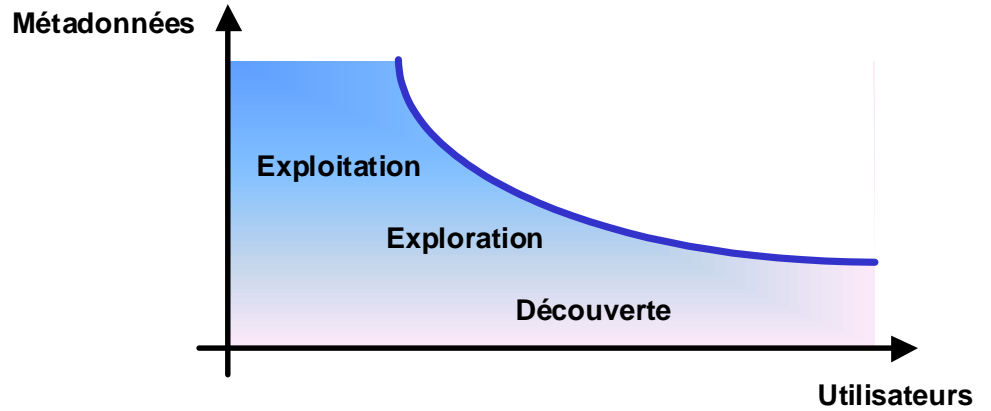

Source : [CNIG 2006], p. 11
- Few metadata are necessary for discovering purpose. They are useful for a large population to identify available resources;

- Exploration metadata help to choose those really answering their needs.

Few users are concerned by metadata implementation which are necessary to configure the information system interface so that it can process the data.

Metadata can be highly recommended in all these professions and at the junctions with one other. 


\subsection{Taking into account the cost and value of information}

The cost of production and maintenance of information and the value of this information are closely linked to its potential uses.

As an example, the production cost of an IFC file may be more expensive than an equivalent DWG file. Nevertheless, the exchanges between CAD and CAFM systems will be easier and a facility manager will accept to spend more in order to save time and money [Gallaher \& al., 2004].

We have highlighted the interest of knowing what is the quality of the information produced or handled, what are the possible consequent added values in term of costs and, above all, of quality of what is being analysed or produced [Ferriès \& Léglise, 2004].

\subsection{Ensuring reliable Information quality}

The notion of metadata and of quality of information is linked with the notion of confidence in the data: if you do not trust an information system you cannot simply use it.

Whatever the world, an information system must be updated, and upgraded thanks to internal and/or external resources. If these resources are undervalued, you are bound to fail: an illmaintained information system gradually loses ground together with the level of confidence of its users.

If one applies the lessons gained from facility management experience to the urban context, the prerequisites for success can be defined as follows:

(1) Choose the right level of definition (the lack of upper threshold can lead to the design of the "map of the empire"...) which is closely interrelated with the end goal of the information system

(2) Set-up an operative updating system and not underestimate the necessary means to do so.

\subsection{Facilitating cooperation while respecting the different cultures and professions}

GIS and CAD/FM tools are well tailored to the different professions; their functionalities and structures do not require major changes but they must be designed to enable their user equipped with the tools of one family to request Web services supplied by the tools of another family.

It sounds unrealistic and useless to change cultures and know-how. The cost of changes and of training would be out of reach. On the contrary, interoperability helps to guarantee the respect for representation modes and know-how in each profession and encourages the development of knowledge in each field with the same degree of respect for methods and modes of representation.

\subsection{Accepting heterogeneities without ignoring them}

Let's take the following example. If I have:

- existing buildings described in LOD1 bought to a geographic information provider

- $\quad$ existing buildings described in LOD3 by an internal service

- $\quad$ planned buildings described in LOD4 from an IFC model supplied by an architect

I want to be able to visualise them together and also to filter (the buildings for which we have a full IFC representation, the buildings updated in the last twelve months by the department, etc...)

We can illustrate this by a counter-example and an example: 

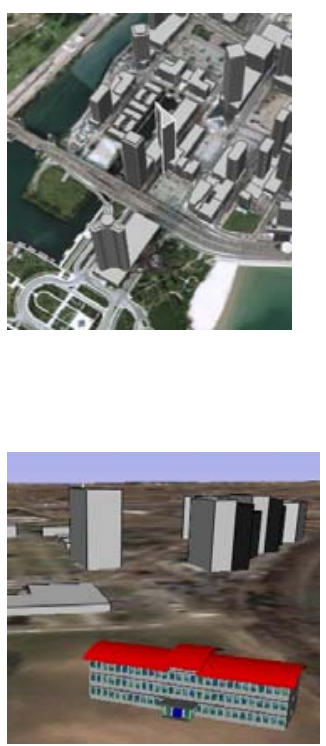

Tutorial work by first-year students of ENSAT ${ }^{20}$ :

They had to insert a virtual building into a site and to visualize the whole thing with Google Earth. In fact, it is impossible to make the distinction between the virtual building and any other building from an American city, all being at the same level of detail (LOD1).

This is really a counter-example of what we try to achieve.

Insertion of a building described in IFC then converted into KML format.

The buildings represented with a lower level of detail describe the INSA campus in Toulouse and have been published in 3D WareHouse.

\subsection{Matching information with stakeholders' viewpoints}

Let us recall the main goals of CityGML: "The aim of the development of CityGML is to reach a common definition of the basic entities, attributes, and relations that can be shared over different applications. This is especially important with respect to the cost-effective sustainable maintenance of $3 \mathrm{D}$ city models, allowing tosell the same data to customers from different application fields. The targeted application areas explicitly include city planning, architectural design, tourist and leisure activities, environmental simulation, mobile telecommunication, disaster management, homeland security, vehicle and pedestrian navigation, and training simulator" [CityGML, 2006]

It is not quite certain from what we have just stated that the same data can be shared without having the point of view of each field or even of each actor on these data.

This brings us back to the importance of metadata which would sort out data selectively and of integrating metadata to the IFC model.

\subsection{Attaching Metadata to an IFC file}

The formalization of metadata in IFCs is still a weak point. The OwnerHistory class keeps records on the user and the application which have generated the data or their modification, the date of creation of the object and that of the latest modification so that the successive contributors can be traced back. OwnerHistory is a mandatory attribute of the IfcRoot and is thus applicable to many derived classes. Yet there is still a lack of information on the quality of data.

An IFC file includes one or several buildings which means it can describe a building as well as a district in a city. The contents of the file can be considered as a set of geographical data (Dataset) and the ISO 19115 norm could help to connect metadata to an IFC file, as suggested on the table below :

\footnotetext{
${ }^{20}$ École Nationale Supérieure d'architecture de Toulouse
} 


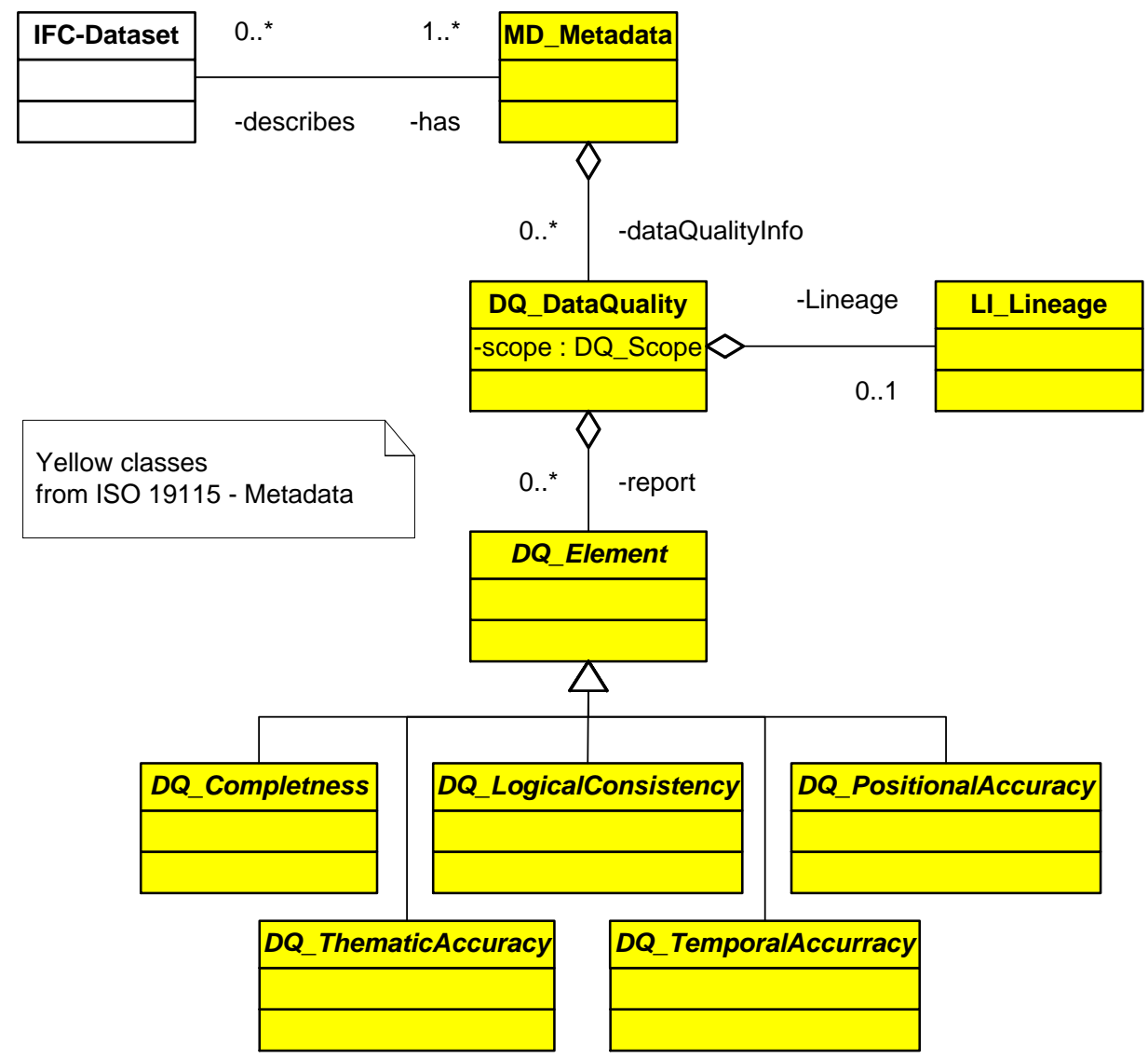

Most concepts defined in the standard can qualify the whole contents of an IFC file or part of it:

- genealogy (e.g result from survey, project modelling...)

- field of application (e.g a specific building)

- exhaustiveness ( e.g the district is described entirely)

\subsection{Designing economically viable solutions}

In order to have high quality data collected in situ or resulting from a synthesis, contributors must be paid for their supply. Otherwise, data are never really updated or lack homogeneity and metadata are less and less used and run which soon makes obsolete all the efforts made to introduce them.

\subsection{Going on developing while taking into account heterogeneities}

In compliance with the principle of mutual respect of worlds and professions, developments must always bring something new by questioning the previous models and suggesting new ones. CityGML level of details is an excellent and operational idea. One may wonder whether this provision "CityGML files can - but don't have to - contain multiple representations for each object in different LOD simultaneously.", [CityGML, 2006], is sensible or not, useful or not according to the professions. One could envisage maintaining the coherence of a view at a given time, which implies homogeneity in the levels of definition for all the buildings of this view. In the same way one can wonder whether it would not be a good idea to extend the LOD scale. Level 4 corresponds to the inside of the building (see [cityGML 2006] - Interoperable Access to 
3D City models, page 10). Why not define levels 5,6 , etc... with the occupants in level 5 for example?

Would it not be more relevant if LOD stood for "Level of definition" instead of "Level of detail" ? because we are dealing with a real level definition of the representation rather than with a detail which could be visualized with a larger zoom.

\section{Conclusion}

In order to be able to act on the world, one should avoid being hampered by all the world data and being paralysed by the multitude of heterogeneous data.

Representation is an abstraction thanks to which tools adapted to each profession can be moulded. Each profession must be allowed its own culture and know-how but each profession must be given the means to cooperate with others in order to score greater achievements: for a better architecture, a better town-planning, better transport, better integrations to the site. Existing tools must remain tailored to the size of regions and scales and thus escape the danger of "generalist" software which could be used at any scale but which would be devoid of the knowledge specific to each profession or which would overflow with useless knowledge of all the professions. Each data must say what it is and must be described, recognized as valid or not, reliable or not by such or such a software or interface.

The map could be potentially as large as the territory but it could not be better controlled than the territory itself taken as a whole.

Jorge Luis Borges, writing a fake attributed to Suarez Miranda in the 17th century, wrote a beautiful fable which gives us food for thought on our subject :

"In that Empire, the art of Cartography reached such perfection that the Map of one Province alone took up the whole of a City, and the Map of the Empire, the whole of a Province. In time, those unconscionable Maps did not satisfy, and the Colleges of Cartographers set up a Map of the Empire which had the size of the Empire itself and coincided with it point by point.

Less Addicted to the Study of Cartography, succeeding Generations understood that this widespread Map was useless and not without Impiety they abandoned it to the inclemencies of the sun and of the winters. In the deserts of the West some mangled ruins of the Map lasted on, inhabited by animals and Beggars; in the whole Country there are no other relics of the Disciplines of Geography."

[Borges, 1935].

Instead of trying to rebuild the whole territory, one should try to design abstraction means which will enable us to act on useful (operating) representations of the world and thus to project real modes of action on this world. 


\section{Bibliography}

- Bernard, M., Ferries, B., Laurini, R., Ourties, S., « SIG \& CAO-DAO, Vers des Systèmes d'Information du Patrimoine », Rapport final d'une recherche financée par le Plan Construction et Architecture, Décision N 0592131, Ministère de l'Equipement et du Logement, France, 1993.

- Bernard, M., Ferriès, B., «SIG, CAO, GP... Quels logiciels pour aménager, construire, gérer? », Urb. $A O N^{\circ}$ 3, Mars 2001.

- Borges, J.L., Histoire universelle de l'infamie, De la rigueur de la Science, Suarez Miranda, Viajes de Varones Prudentes, liv. IV, chap. XLV, Lérida, 1658, (1935).

- CityGML, 2006 ; homepage : www.citygml.org

- Denègre J., Le serveur éducatif de I'IGN et de I'Education Nationale sur l'information géographique, fiche « Information géographique : définition, typologie, exemple », 2006

http://seig.ensg.ign. fr/index.php3?RPHP $=\& R C O=\& R C H=\& R F=\& R P F=\& R P C=$.

- d'Erceville, H., «Pagesjaunes.fr entre dans la troisième dimension », 01 Informatique, sept 2006.

http://www.01net.com/article/325523.html?rss

- Ferriès, B., Les Métadonnées, Dossier technique de la revue SIG et Télédétection, n¹4, juillet 95.

- Ferriès, B., Léglise. M., Et si l'on adoptait une démarche HQI ?, $7^{\text {eme }}$ Symposium de I'Innovation des Technologies de I'Information dans la construction, Clermont Ferrand, 25/9/2003, repris dans «Le guide Bâtiment 2005 », disponible sur http://www.laurenti.com/publis/iBatiment.pdf.

- Ferriès, B., « Propositions pour améliorer l'interopérabilité entre Systèmes d'Information du Bâtiment et Systèmes d'Information Géographique », Étude exploratoire pour le compte de Mediaconstruct, Février 2004.

- Gallaher , M.P. O'Connor, A.C., Dettbarn, J.L, Gilday, LT, « Cost analysis of Inadequate Interoperability in the U.S. Capital Facilities Industry", August 2004, http://www.bfrl.nist.gov/oae/publications/gcrs/04867.pdf

- Goulette J.P., Léglise M., Pérez M., Le poste architecte : spécifications, session d'utilisation, présentation de la maquette et documentation in Krépis, Rapport final de recherche, Toulouse, CAOMIP, Rapport final d'une recherche financée par le Ministère de l'Équipement, du Logement, de l'Aménagement du Territoire et des Transports dans le cadre du programme IN.PRO.BAT., juin 1988 ; 45 p.

- Kolbe T. H., Plümer L. "Bridging the Gap between GIS and CAAD", GIM International, No. 7, 2004 ; http://www.citygml.org/docs/GIM-Artikel7_04.pdf

- Krépis, Rapport final de recherche, Toulouse, CAOMIP, Rapport final d'une recherche financée par le Ministère de l'Equipement, du Logement, de l'Aménagement du Territoire et des Transports dans le cadre du programme IN.PRO.BAT., Juin $1988 ; 45$ p.

- Mapinfo, User's Manual, V8, MapInfo Corporation, 2006. Voir aussi :

http://reference.mapinfo.com/software/mapinfo_pro/english/8.5/MI_UG.pdf

- Miller, B., Moulton, A., «ArcGIS® - ArchiCAD - Prototype Proposal for Data Exchange », Industry Day, Session AEC + FM information technology to support Homeland Security, Washington, USA, 14 mai 2003. http://www.iai-na.org/technical/industryday.php 
